\title{
Optimal Grain Size Based Landscape Pattern Analysis for Shanghai Using Landsat Images from 1998 to 2017
}

\author{
Jia Wang ${ }^{1}$, Long Li ${ }^{1,2}$, Ting Zhang1, Longqian Chen ${ }^{1 *}$, Mingxin Wen ${ }^{1}$, \\ Weiqiang $\mathrm{Liu}^{3}$, Sai $\mathrm{Hu}^{4}$ \\ ${ }^{1}$ School of Public Policy and Management, China University of Mining and Technology, \\ Daxue Road 1, Xuzhou 221116, China \\ ${ }^{2}$ Department of Geography, Earth System Science, Vrije Universiteit Brussel, Pleinlaan 2, 1050 Brussels, Belgium \\ ${ }^{3}$ School of Environmental Science and Spatial Informatics, China University of Mining and Technology, \\ Daxue Road 1, Xuzhou 221116, China \\ ${ }^{4}$ School of Humanities and Law, Jiangsu Ocean University, Cangwu Road 59, Lianyungang 222005, China
}

Received: 25 May 2020

Accepted: 1 November 2020

\begin{abstract}
While they are an effective tool for studying landscape patterns and describing land-use change, landscape metrics are sensitive to variation in spatial grain sizes. It is therefore crucially important to select an optimal grain size for characterizing urban landscape patterns. Due to accelerated urbanization, Shanghai, the economic capital of China, has seen drastic changes in landscape patterns in recent decades and it would be interesting to take Shanghai as an example for examining the grain effect of landscape patterns. In this study, from Shanghai's land use maps derived from Landsat images of 1998, 2007, and 2017 via random forest classification, a selection of landscape metrics was measured with 14 grain sizes ranging from $30 \mathrm{~m}$ to $460 \mathrm{~m}$. Both the conventional first scale domain method and the information loss evaluation model were adopted to comprehensively determine an optimal grain size for characterizing Shanghai's landscape pattern. After that, the land use dynamic degree model was used to explore the change in Shanghai's landscape pattern under the optimal grain size. Results demonstrate that (1) the responses of landscape metrics varied with grain size, which could be divided into three categories, namely irregular trend, decreasing trend, and no clear change; that (2) the optimal spatial grain size for landscape pattern analysis was $60 \mathrm{~m}$; and that (3) the degree of landscape aggregation decreased, whereas that of landscape diversity and fragmentation increased. This study shows a clear grain effect of landscape patterns and can provide useful insights for urban landscape planning.
\end{abstract}

Keywords: grain effect, grain size, landscape pattern, landscape metrics, Shanghai

*e-mail: chenlq@cumt.edu.cn 


\section{Introduction}

As a key issue that both geography and ecology need to address, scale has been considered one of the ten focuses in the field of landscape ecology in the $21^{\text {st }}$ century [1]. While the complexity and variability of landscape elements explain spatial heterogeneity, the landscape pattern of the same landscape varies with scale [2-4]. Therefore, the scale effect of landscape patterns must be considered in the studies on landscape pattern change [5]. The scale consists of extent and grain; the former refers to the continuous range of the object in terms of space and time, whereas the latter refers to maximum resolution or pixel size $[6,7]$. The extent effect is observed when landscape pattern analysis results change with the size of the observed unit area [8] and the grain effect refers to the variation of the results with grain size which may change due to data aggregation $[9,10]$. Accordingly, some researchers have attempted to unravel the response of landscape patterns to the change in scale and evaluate ecosystem services at multiple scales [11].

Landscape metrics are useful for characterizing landscape patterns and their spatial heterogeneity $[5,12-$ 14] in the studies areas such as watershed areas [15], Mediterranean arid areas [16], and forest reserves [17]. The majority of landscape metrics are scale-dependent and sensitive to grain size [18-22], i.e. their calculated values are related to the cell size (sometimes aka spatial resolution) of land-use data $[5,23]$. Landscape metrics derived at different grain sizes are likely to present contrasting landscape patterns in the studies on landscape structures, ecological processes, and ecosystem services [24]. Thanks to the development of remote sensing (e.g. ENVI) and landscape analysis software (e.g. FRAGSTATS), it has become increasingly convenient to examine the grain effect of landscape metrics [25-27]. For example, Fang et al. [5] examined the landscape patterns of arid valleys in China based on grain effect. Connor et al. [28] explored the effects of grain sizes on landscape simulation in Scandinavian Mountains in Norway, Sweden, and southern Finland. Lü et al. [29] performed a grain analysis of the minor watershed landscape on the Loess Plateau and compared varied re-sampling methods. It would be also interesting to investigate how landscape metrics respond to various grain sizes in an urban context [30]. While some researchers have classified the responses of landscape metrics into three different categories, namely predictable response, unstable response, and step-like response [31, 32], a finer classification of the responses also exists in some other studies [5, 16]. Even for the same landscape metric, the response to grain size change is somewhat divergent because of different grain sizes tested [10, 33, 34]. Nevertheless, understanding the responses of landscape metrics would help to identify an optimal grain size for landscape pattern analysis.

Multiple methods for determining an appropriate grain size for landscape pattern analysis have been proposed such as the first scale domain method [3537] and the information loss evaluation model [38, 39]. The former method is extensively used because of convenience and simplicity but considered subjective $[5$, 22]. The latter method is used to quantify the amount of lost information induced by data re-sampling [10,29] and a grain size that corresponds to the least information loss can be selected as suitable for landscape pattern analysis. However, it focuses on the loss of spatial data but ignores the expression of landscape pattern features. Since both the methods have their own (dis)advantages, it would be better to use them together to identify an optimal grain size, which has been favored in some previous studies $[22,40]$. With an optimal grain size, landscape pattern analysis can effectively reveal landscape pattern components, and equally importantly, allows for a characterization of landscape pattern change with least reduced information $[8,37]$.

This study aims at revealing the grain effect of landscape metrics by selecting Shanghai with Landsat image data over this Chinese metropolis acquired from 1998 to 2017, for a case study. The specific objectives of this study are as follows: (1) to explore the response of landscape metrics to the change of grain size; (2) to determine an optimal grain size for landscape pattern analysis by jointly applying the first scale domain method and the information loss evaluation model; and (3) to characterize landscape patterns under the optimal grain size by using the land use dynamic degree model.

\section{Study Area and Data}

\section{Study Area}

Bordering the provinces of Jiangsu and Zhejiang, Shanghai is situated on the banks of the Yangtze River Delta in East China $\left(120^{\circ} 52^{\prime}-122^{\circ} 12^{\prime} \mathrm{E}\right.$ and $30^{\circ} 40^{\prime}-31^{\circ} 53^{\prime} \mathrm{N}$ ) (Fig. 1) with an average altitude of $\sim 4 \mathrm{~m}$. Shanghai is characterized by a subtropical monsoon climate with an average annual temperature of $17.5^{\circ} \mathrm{C}$ recorded in 2017 [41]. As of 2017, Shanghai has an area of $6340.5 \mathrm{~km}^{2}$ and consists of 16 districts, divided into central urban areas (CUA) and suburbs.

In addition to being one of the four municipalities in China, Shanghai is the core of the Yangtze River Delta urban agglomeration and the economic, commercial, financial, innovation, and transportation centers of China. The total residents in Shanghai had reached 24.18 million in 2017, ranking the most populous urban area in China [41]. The gross domestic product (GDP) in Shanghai rose from 380.11 billion RMB in 1998 to 3063.30 billion RMB in 2017 with the tertiary industry accounting for $69 \%$ of the 2017 GDP [41]. Due to population growth and economic development, Shanghai saw a significant land use change in the nearly two decades as a result of mainly human activity [42]. And according to the Shanghai Master Plan 2017-2035, it is committed to building a more sustainable eco-city with 


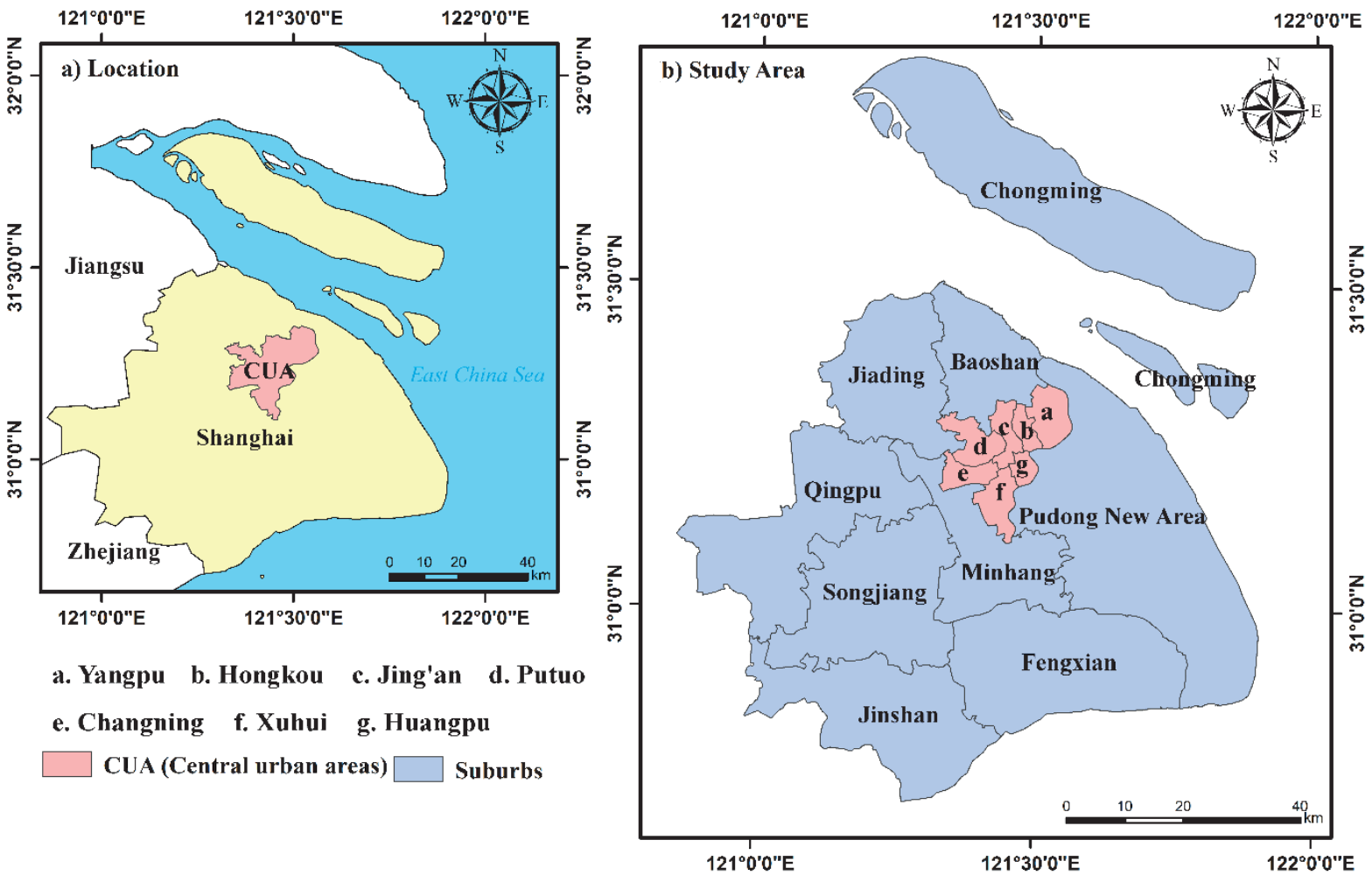

Fig. 1. a) The location of Shanghai in East China; b) the 16 districts of Shanghai.

green spaces and low-carbon infrastructures, which necessitate studying Shanghai's landscape pattern over time [43]. Considering its natural and socio-economic characteristics, Shanghai is an ideal area for this study for urban pattern analysis.

\section{Remote Sensing Images}

As remote sensing is useful for observing changes in land use and vegetation cover over a wide area [44, 45], satellite remote sensing image data were collected for producing land use maps and deriving landscape metrics. They consist of 30-m-resolution Landsat $5 \mathrm{TM}$ and Landsat 8 OLI, all freely downloaded from the U.S. Geological Survey website (https://earthexplorer.usgs. gov/) (Table 1). Due largely to image quality and the large area of Shanghai, Landsat images acquired in the summers of 1998, 2007, and 2017 were selected and we assume the effect of the small date intervals on image classification would be limited [46].

Prior to classification, the images were pre-processed in ENVI 5.3 for atmospheric correction, geometric correction (image to image), and image mosaicking. Finally, the vector data of Shanghai's administrative boundaries were used to extract the study area for image classification and further analysis.

\section{Methods \\ Land-Use Mapping \\ Random Forest Classification}

Random forest (RF) was selected for urban land use classification in this study as it is a superior classifier in producing accurate results for various purposes, e.g. mapping lava flow of different age [47], regional land use [48], urban vegetation types [49], and volcanic risk assessment [50]. The number of trees (ntree) and random features (mtry) are two important parameters in RF classification and usually determined by trial and error [51]. By using the RF classification plug-in EnMAP-Box in ENVI 5.3 [52], we set ntree and mtry at

Table 1. Landsat image data used in the study.

\begin{tabular}{|c|c|c|}
\hline Year & Sensor & Acquisition Date (Path/Row) \\
\hline 1998 & Landsat 5 TM & $1998-08-04(118 / 038), 1998-08-04(118 / 039)$ \\
\hline 2007 & Landsat 5 TM & 2007-07-28 (118/038), 2007-07-28 (118/039) \\
\hline 2017 & Landsat 8 OLI & $2017-08-24(118 / 038), 2017-08-24(118 / 039)$ \\
\hline
\end{tabular}


100 and 3, respectively, as the optimal parameters and produced three land use maps for Shanghai, following the study by Cui et al [48], with six broad classes, namely cropland, urban land, forestland, grassland, water area, and other land-use (Fig. 2).

\section{Accuracy Assessment}

High-resolution satellite images in Google Earth Pro were used for extracting reference data required for the accuracy assessment of the land use classification. A total of 350 random sample points were generated over the study area in ArcGIS 10.2 and then laid over the produced land use maps (Fig. 2) for extracting classified land use types. To produce reference data, these points were also imported into Google Earth Pro and the land use type for each point was determined by visually interpreting the Google Earth satellite images. Finally, a confusion matrix for each land-use classification was created for calculating the overall accuracy and Kappa coefficient, which were $88.027 \%$ and 0.824 for the 2007 land use map and $88.385 \%$ and 0.839 for the 2017 land use map, respectively. The classification results were similar and high (Kappa coefficients >0.70) [48, 53], which were considered acceptable. It is noted that no independent accuracy assessment was performed for the 1998 land use map because of no high-resolution satellite images of 1998 over Shanghai in Google Earth Pro. However, since the classification methods and procedures were consistent for all the classifications, we assumed that the accuracy of the 1998 land use map was similar to those of the 2007 and 2017 land use maps [48].

\section{Landscape Metrics and Scale Dependence}

\section{Landscape Metrics}

While landscape metrics can be classified into three levels, i.e. the patch, class, and landscape level [54], landscape pattern analysis is usually performed at the class and landscape levels [9, 22]. There are
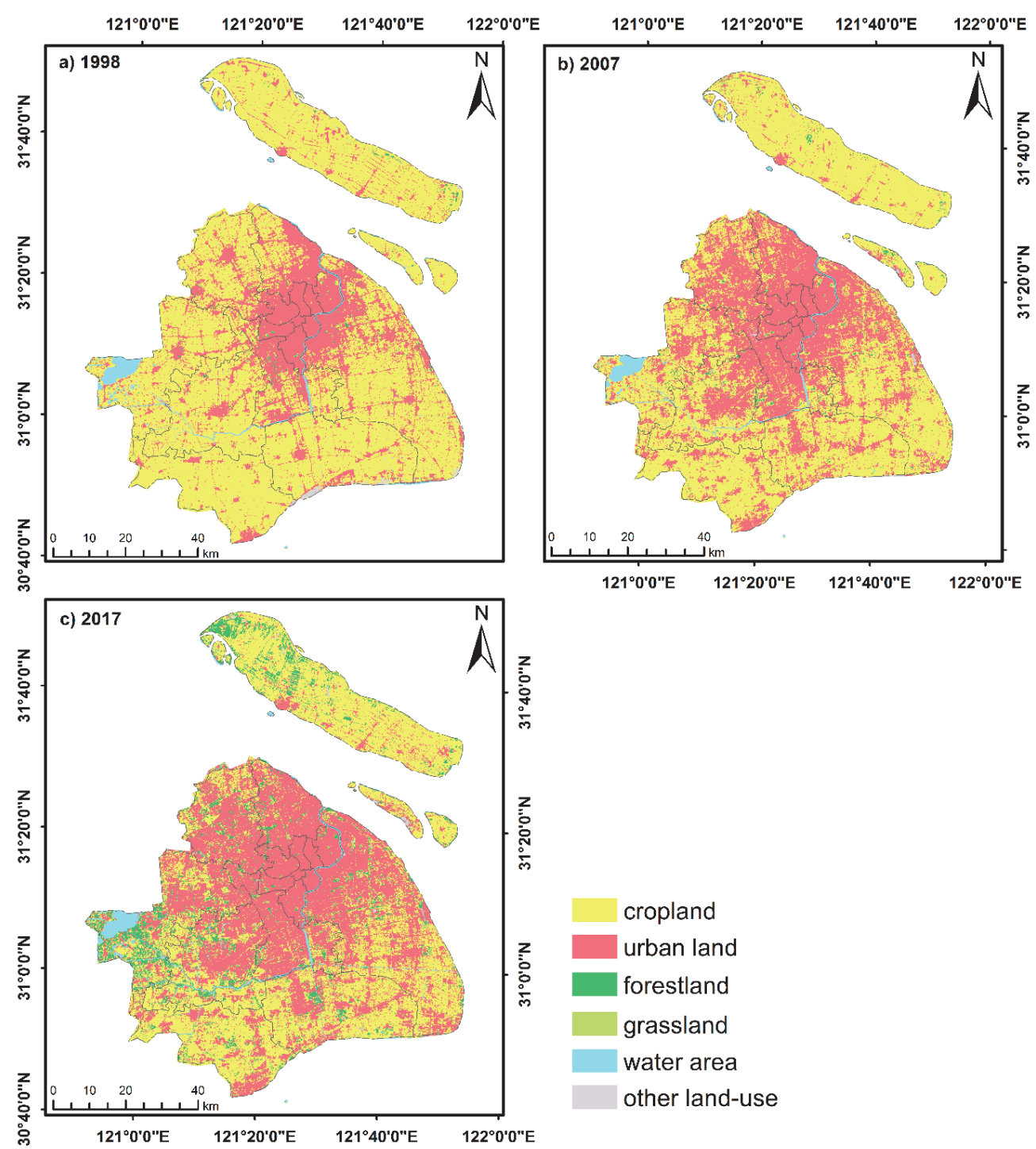

Fig. 2. Shanghai's land use maps of 1998 a), 2007 b), and 2017 c). 
Table 2. Landscape metrics used in this study and their descriptions.

\begin{tabular}{|c|c|c|}
\hline Level & Landscape metrics & Description \\
\hline \multirow{4}{*}{$\begin{array}{c}\text { Tlass-level } \\
\text { metrics }\end{array}$} & Aggregation index (AI) & $\begin{array}{c}\text { It is based on the length of adjacent boundaries among the same type of plaque pixels } \\
\text { to determine the degree of plaque aggregation and dispersion. }\end{array}$ \\
\cline { 2 - 4 } & Edge density (ED) & It refers to the length of a certain landscape type boundary in a unit area. \\
\cline { 2 - 4 } & $\begin{array}{c}\text { Landscape shape index } \\
\text { (LSI) }\end{array}$ & It reflects the complexity of the shape of the patch by calculating the degree of shape \\
& deviation.
\end{tabular}

48 class-level metrics and 57 landscape-level metrics, all of which can be computed in spatial pattern analysis software FRAGSTATS 4.2 [55]. Because of information redundancy between these landscape metrics, we referred to multiple previous studies [56-59] and selected eight class-level and four landscape-level metrics (listed in Table 2 with their descriptions). The selected landscape metrics, which are widely used in the context of urban landscapes, can reveal the distinctions of the urban landscape from various perspectives, such as the area, aggregation, shape, patch density, and separation of landscape types in the study area, as well as the overall heterogeneity, sprawl, and patch density of the landscape.

\section{Grain Size Setting}

To study the influence of grain size on landscape metrics, we first converted the land-use data into GRID data format in ArcGIS 10.2 and then imported it into FRAGSTATS 4.2 to calculate the 12 landscape metrics. Given the spatial resolution of Landsat image data, the geographical area of the study area, and the effect of the re-sampled image, we selected 14 grain sizes for re-sampling by using the majority re-sampling method in ArcGIS 10.2, ranging from the original spatial resolution $30 \mathrm{~m}$ to the maximum $460 \mathrm{~m}$ with different increments. The selection of grain sizes vary from study to study, for example, using a series of grain sizes which constitute an arithmetic progression (i.e. an equal interval between each grain size and the one before) or a geometric progression (i.e. a constant ratio between each grain size and the one before) [8, 29, 60]. This is because some landscape features can only be observed at a specific grain size [27]. In the context of Shanghai, we set three different grain size increments, $15 \mathrm{~m}$ from $30 \mathrm{~m}$ to $90 \mathrm{~m}, 30 \mathrm{~m}$ from $90 \mathrm{~m}$ to $210 \mathrm{~m}$, and $50 \mathrm{~m}$ from $210 \mathrm{~m}$ to $460 \mathrm{~m}$, and then produced 14 land-use grids of different grain sizes after re-sampling. As the grain size increased (i.e. the spatial resolution of the land use map decreased), spatial details also decreased [5]. The calculated landscape metrics corresponding to different grain sizes were imported into the graphing software OriginPro 9, and the response curves of landscape metrics against grain sizes were generated to explore the grain effect of landscape metrics.

\section{Measuring the Sensitivity of Landscape Metrics to Grain Size Change}

In addition to the response curves of landscape metrics, the coefficient of variation $(\mathrm{CV})$ is also effective in revealing the sensitivity of landscape metrics to different grain sizes [8,9] and was used in this study. The $\mathrm{CV}$ is the proportion of the standard deviation to the average of the data, providing a standard measure for objective comparison of landscape metrics [21]. The $\mathrm{CV}$ of each observed landscape metric was calculated in the statistical software SPSS 22 using the following formula: 


$$
\mathrm{CV}=\sqrt{\frac{1}{n} \sum_{i=1}^{n}\left(x_{i}-\frac{1}{n} \sum_{i=1}^{n} x_{i}\right)^{2}} /\left(\frac{1}{n} \sum_{i=1}^{n} x_{i}\right)
$$

...where $n$ is the number of grain sizes and $x_{i}$ is the value of the metric at the $i^{\text {th }}$ grain size. When the $\mathrm{CV}$ value is small, the degree of variation is low, that is, the landscape metric is less sensitive to grain size change. We here divided the sensitivity of the landscape metric to grain size change into four levels: insensitivity $(\mathrm{CV}<1 \%)$, low sensitivity $(1 \% \leq \mathrm{CV}<10 \%)$, moderate sensitivity $(10 \% \leq \mathrm{CV}<50 \%)$, and high sensitivity $(50 \% \leq \mathrm{CV}<100 \%)[8]$.

\section{Determining An Optimal Grain Size}

The first scale domain method is often used for determining an optimal grain size for landscape pattern analysis [8, 9]. In a response curve, the first scale domain is a grain size range that is determined by the grain size corresponding to the first and second turning points of the response curve [61]. A grain size slightly larger than the first turning point in the first scale domain should be selected as an optimal one, which retains more landscape information while requiring less data-processing time [5].

When re-sampling a land-use map to coarse grain sizes, spatial details will lose [27] and landscape pattern analysis will be undermined. This suggests the grain size that induces the least information loss can be considered optimal. To measure the overall information loss degree of landscapes in the re-sampling process, The information loss evaluation model [38, 40] was adopted here:

$$
\left\{\begin{array}{l}
P=\left|100 \times M / A_{b}\right| \\
M=\sum_{i=1}^{n}\left|A_{g i}-A_{b i}\right|
\end{array}\right.
$$

...where $P$ is the information loss percentage for a landscape metric, $M$ is the total information loss for the landscape metric, $A_{b}$ is the sum of the metric value for all landscape types on the base data $(30 \mathrm{~m}$ spatial resolution, before re-sampling), $A_{g i}$ is the corresponding data value of the metric for a category $i$ landscape, $A_{b i}$ is the metric value for category $i$ landscapes on the base data, and $n$ is the total number of landscape types.

Since the response of landscape metrics to different grain sizes change subtly over time [62], the optimal grain size was determined through the analysis of the class-level metrics derived from the latest data for better data currency and more practical significance $[5,8]$, which was in the year of 2017. In this study, both the first scale domain method and the information loss evaluation model were used to find respective optimal ranges of grain sizes and the overlap between the two optimal ranges was identified as an optimal grain size for landscape pattern analysis.

\section{Analysis of Shanghai's Landscape Pattern}

After the identification of an optimal grain size, the land use dynamic degree (LUDD) model was used to explore the change of Shanghai's landscape pattern from 1998 to 2017. Land use dynamic degree (LUDD) can measure the rate of land-use change, compare the differences in specific areas, and predict the landscape pattern trend [39, 63]. LUDD consist of the single land use dynamic degree $(K)$ and the overall land use dynamic degree $\left(K_{S}\right)$ [64]. The single land use dynamic degree $K$ refers to the change rate of a certain type of land use during a specific period, reflecting the speed and magnitude of the change. It is calculated as follows [39]:

$$
K=\frac{U_{b}-U_{a}}{U_{a}} \times \frac{1}{T} \times 100 \%
$$

...where $U_{a}$ and $U_{b}$ are the areas of a land-use type at the beginning and end of the study period, respectively; $T$ is the interval of the study period. If $T$ is 1 year, then $K$ refers to the annual change rate.

The overall land use dynamic degree $K_{S}$ measures the overall land use change rate during a certain study period. A larger $K_{S}$ values means a more intensive landuse change. It is given as follows [39]:

$$
K_{s}=\left(\frac{\sum_{i-1}^{n} \Delta L U_{i-j}}{2 \sum_{i=1}^{n} L U_{i}}\right) \times \frac{1}{T} \times 100 \%
$$

...where $L U_{i}$ is the total area of land-use type $i$ at the beginning, $\Delta L U_{i-j}$ is the absolute value of the total area change of type $i$ to type $j$ during the study period, and $T$ is the interval of the study period.

\section{Results}

\section{Responses of Landscape Metrics to Grain Size Change \\ Responses of Class-level Metrics to Grain Size Change}

The CV (coefficient of variation) values of the classlevel metrics for Shanghai in 2017 were calculated (Table 3). The majority of the measured landscape metrics (over $83 \%$ ) were sensitive $(\mathrm{CV} \geq 1 \%$ ) to grain size change. Overall, the landscape metric most sensitive to grain size change was PD (mostly highly sensitive), followed by LSI and ED (both moderately sensitive). However, the landscape metrics with small $\mathrm{CV}$ values include CA and DIVISION, which indicating their low or no sensitivity to grain size change. Moreover, for the same landscape metric, the $\mathrm{CV}$ value varied largely 
Table 3. The CV (coefficient of variation) values of the class-level metrics for Shanghai in 2017.

\begin{tabular}{|c|c|c|c|c|c|c|c|c|}
\hline Land-use & CA (\%) & LPI (\%) & PD (\%) & AI (\%) & COHESION (\%) & DIVISION (\%) & LSI (\%) & ED (\%) \\
\hline cropland & 1.007 & 26.625 & 75.021 & 10.247 & 0.411 & 1.932 & 32.654 & 33.430 \\
\hline urban land & 0.221 & 21.417 & 67.423 & 9.421 & 0.332 & 2.909 & 29.038 & 29.592 \\
\hline forestland & 2.507 & 8.977 & 67.576 & 38.452 & 12.853 & 0.004 & 33.772 & 35.311 \\
\hline grassland & 5.933 & 8.453 & 79.716 & 66.859 & 52.161 & 0.000 & 41.574 & 44.374 \\
\hline water area & 1.330 & 7.244 & 48.430 & 20.328 & 8.264 & 0.000 & 22.967 & 23.970 \\
\hline other land-use & 6.958 & 11.197 & 84.190 & 52.396 & 37.344 & 0.000 & 41.275 & 44.437 \\
\hline
\end{tabular}

Higher CV values indicate that the metrics are more sensitive to grain size change. High sensitivity values $(50 \% \leq \mathrm{CV}<100 \%)$ are shaded in dark green, moderate sensitivity $(10 \% \leq \mathrm{CV}<50 \%)$ in light green, and low sensitivity $(1 \% \leq \mathrm{CV}<10 \%)$ in whitish green.

with land-use type. For example, the COHESION was highly sensitive to grain size change for grassland but showed much less sensitivity for cropland, urban land, and water area.

The eight class-level metrics responded differently to increasing grain size. In FRAGSTATS 4.2, we derived the eight metrics under the 14 different grain sizes from the 2017 land-use map of Shanghai and plotted the response curves of metrics against grain size in OriginPro 9 (Fig. 3). The response curves could be classified as three broad types:

1. Type I: Irregular trend, e.g. the response curves of LPI and DIVISION for cropland and urban land. These curves had obvious turning points at $60 \mathrm{~m}$,

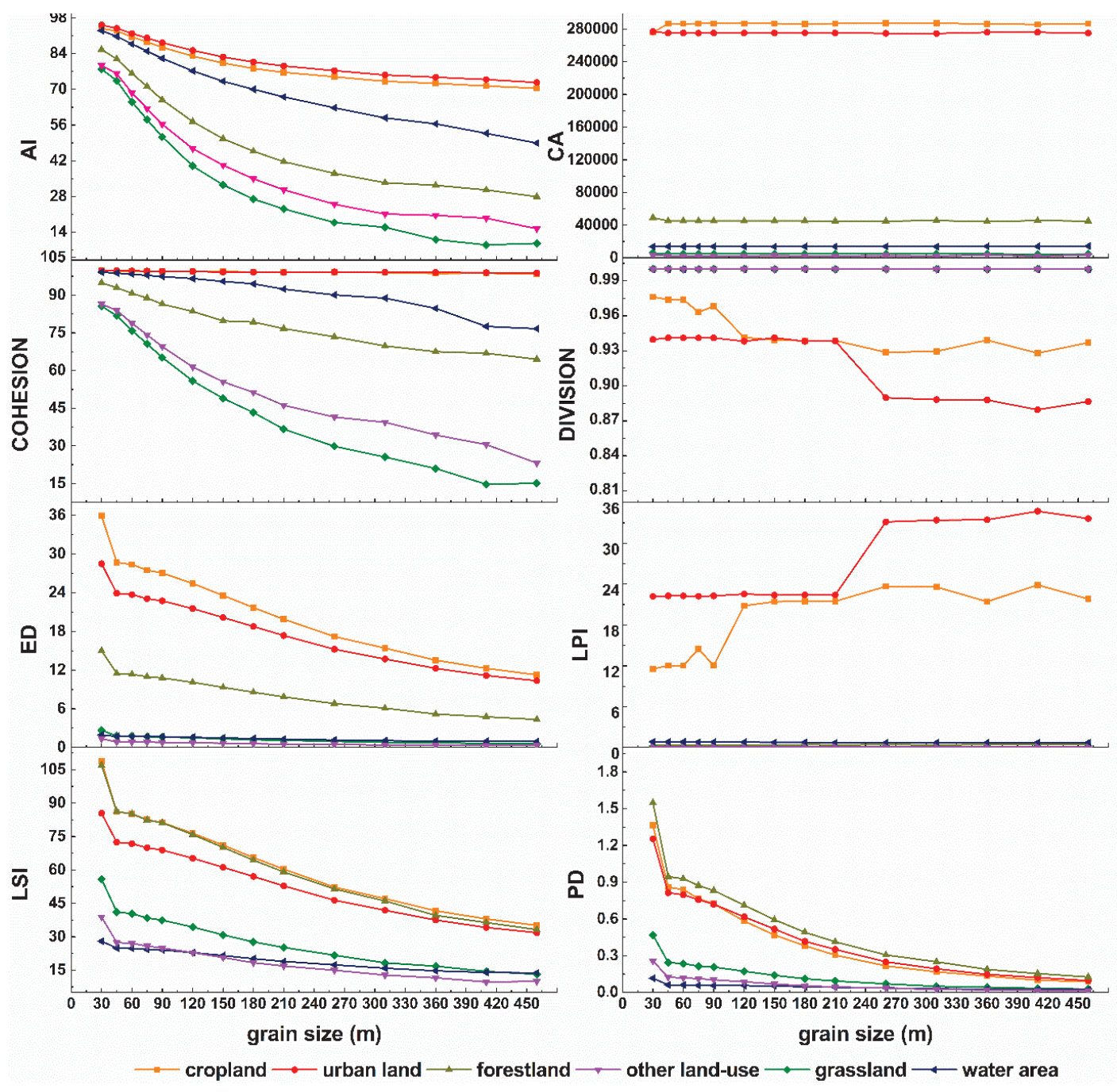

Fig. 3. The response curves of the class-level metrics for Shanghai in 2017. 
Table 4. The first scale domain and the range of appropriate grain sizes for each class-level metric.

\begin{tabular}{|c|c|c|}
\hline Class-level metric & $\begin{array}{c}\text { First scale } \\
\text { domain }\end{array}$ & $\begin{array}{c}\text { Range of appropriate } \\
\text { grain sizes }\end{array}$ \\
\hline CA & - & $\begin{array}{c}\text { A smaller size is } \\
\text { preferred }\end{array}$ \\
\hline AI & $45-210 \mathrm{~m}$ & $60-180 \mathrm{~m}$ \\
\hline ED & $45-90 \mathrm{~m}$ & $60-75 \mathrm{~m}$ \\
\hline LPI & $45-120 \mathrm{~m}$ & $60-90 \mathrm{~m}$ \\
\hline LSI & $45-90 \mathrm{~m}$ & $60-75 \mathrm{~m}$ \\
\hline PD & $45-90 \mathrm{~m}$ & $60-75 \mathrm{~m}$ \\
\hline COHESION & $45-210 \mathrm{~m}$ & $60-180 \mathrm{~m}$ \\
\hline DIVISION & $45-120 \mathrm{~m}$ & $60-90 \mathrm{~m}$ \\
\hline Overlapping & $45-90 \mathrm{~m}$ & $60 \mathrm{~m}$ \\
\hline
\end{tabular}

$120 \mathrm{~m}$, and $210 \mathrm{~m}$, where metrics changed irregularly with grain size.

2. Type II: Decreasing trend, e.g. the response curves of AI, COHESION, ED, LSI, and PD. The curves continuously decreased with grain size but begun to flatten after $260 \mathrm{~m}$.

3. Type III: No clear change. The response curves of CA were almost flat and hardly affected by grain size change.

By analyzing the response curves of the eight classlevel metrics for different land-use types, we obtained the first scale domain and the range of appropriate grain sizes for each metric (Table 4). By comparing the overlapping parts of these ranges, the first scale domain was narrowed down to $45-90 \mathrm{~m}$ and the optimal grain size for landscape pattern analysis at the class level was $60 \mathrm{~m}$.

\section{Responses of Landscape-level Metrics to Grain Size Change}

The CV values of the landscape-level metrics for Shanghai in different years were calculated (Table 5). Among the landscape-level metrics, highest sensitivity to grain size change was found in PD and lowest sensitivity in SHDI and SHEI. Sensitivity also changed over time. For example, the sensitivity of CONTAG was low in 1998 and 2007 but moderate in 2017.

The four landscape-level metrics under the 14 grain sizes in the three years were derived in FRAGSTATS 4.2 and their response curves were plotted in OriginPro 9 (Fig. 4). There were two trends observed for the landscape-level metrics: (1) decreasing, e.g. the response curves of PD and CONTAG, with an obvious turning point at $45 \mathrm{~m}$; and (2) no clear change, e.g. the response curves of SHEI and SHDI, except for a turning point at $45 \mathrm{~m}$. These graphs show that the optimal grain size for landscape pattern analysis at the landscape level was greater than $45 \mathrm{~m}$.

\section{Information Loss Evaluation}

Following the method described in Formula (2), we calculated the information loss for the eight 2017 class-level metrics when they were re-sampled to different grain sizes and plotted the information loss curves in Fig. 5. Overall, information loss increased with grain size and different class-level metrics present contrasting information loss percentages. While PD had the most information loss in re-sampling, DIVISION lost the least information. The eight curves had an obvious turning point at $45 \mathrm{~m}$ and, on the whole, had a relatively stable change between $45 \mathrm{~m}$ and $60 \mathrm{~m}$. When grain size exceeded $60 \mathrm{~m}$, the percentage of information loss changed obviously (e.g. LPI and DIVISION).

Table 5. The CV values of the landscape-level metrics for Shanghai in different years.

\begin{tabular}{|c|c|c|c|c|c|}
\hline Landscape-level metric & Year & Mean & SD & CV (\%) & Response \\
\hline \multirow{3}{*}{ SHDI } & 1998 & 0.712 & 0.006 & 0.899 & Insensitivity \\
\cline { 2 - 6 } & 2007 & 0.822 & 0.005 & 0.594 & Insensitivity \\
\cline { 2 - 6 } & 2017 & 1.053 & 0.006 & 0.565 & Insensitivity \\
\hline \multirow{4}{*}{ SHEI } & 1998 & 0.397 & 0.004 & 0.899 & Insensitivity \\
\cline { 2 - 6 } & 2007 & 0.459 & 0.003 & 0.595 & Insensitivity \\
\cline { 2 - 6 } & 2017 & 0.588 & 0.003 & 0.566 & Insensitivity \\
\hline \multirow{3}{*}{ PD } & 1998 & 0.861 & 0.489 & 56.845 & High sensitivity \\
\cline { 2 - 6 } & 2007 & 0.941 & 0.625 & 66.498 & High sensitivity \\
\cline { 2 - 6 } & 2017 & 1.879 & 1.324 & 70.472 & High sensitivity \\
\hline \multirow{3}{*}{ CONTAG } & 1998 & 69.834 & 3.543 & 5.074 & Low sensitivity \\
\cline { 2 - 6 } & 2007 & 64.546 & 4.197 & 6.502 & Low sensitivity \\
\cline { 2 - 6 } & 2017 & 52.945 & 5.488 & 10.366 & Moderate sensitivity \\
\hline
\end{tabular}



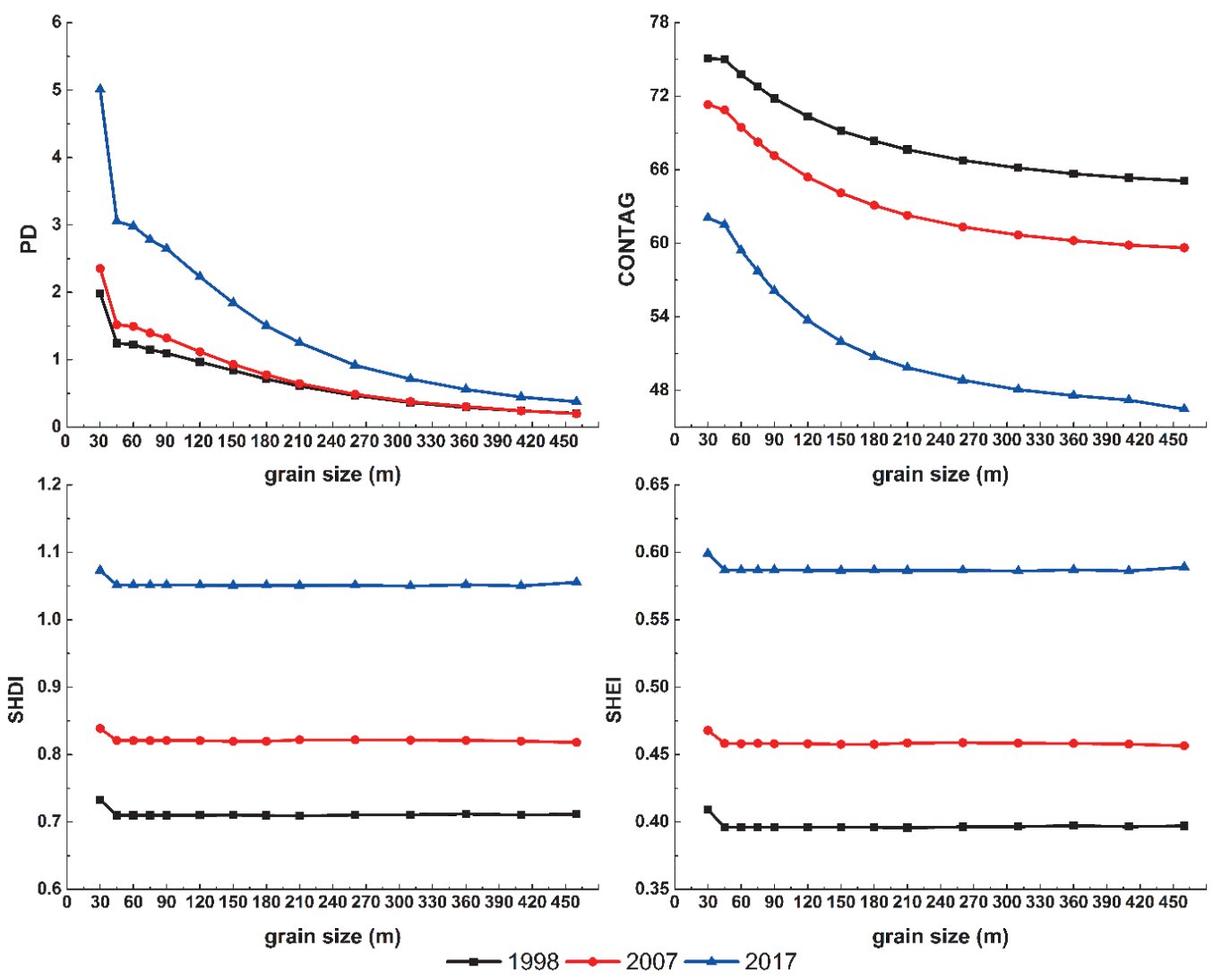

Fig. 4. The response curves of landscape-level metrics for Shanghai in different years.

The results show that information loss was minor within range from $45 \mathrm{~m}$ to $60 \mathrm{~m}$.

\section{Optimal Grain Size}

By combining the appropriate grain sizes determined by the first scale domain method and by the information loss evaluation model, the overlap of them was $60 \mathrm{~m}$ (Table 6). Therefore, the optimal grain size for landscape pattern analysis in the context of Shanghai was $60 \mathrm{~m}$ at both the class level and landscape level.

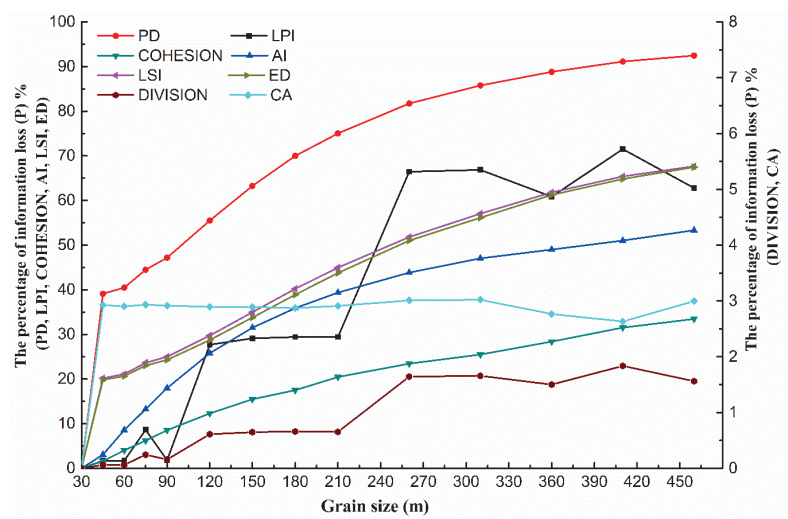

Fig. 5. The information loss for the eight 2017 class-level metrics under different grain sizes.

\section{Analysis of Shanghai's Landscape Pattern}

\section{Land Use Change}

According to the land use dynamic degree model, we computed the single and overall land use dynamic degree for each land use type of Shanghai based on the land use map at the optimal grain size (i.e. $60 \mathrm{~m}$ ) (Fig. 6, Table 7). While grassland had the highest single land use dynamic degree from 1998 to 2007 (25.48\%), forestland had the highest from 2007 to 2017 (70. 44\%) as well as during the entire study period $(74.20 \%)$. In addition, the single land use dynamic degree from 1998 to 2017 was positive for forestland, grassland and urban land but negative for cropland. This indicates that in general both urban green and built-up areas were expanding. The overall land-use dynamic degree of Shanghai was $1.575 \%$ from 1998 to $2007,1.343 \%$ from 2007 to 2017, and 1.428\% from 1998 to 2017.

\section{Landscape Pattern Change over Time}

In order to reflect Shanghai's landscape pattern features under the optimal grain size from 1998 to 2017, we calculated the eight class-level metrics from the 60-m land use maps (Fig. 7). In general, the classlevel metrics varied with land use types and time. Similar changes over time occurred between AI and COHESION, between CA and LPI, and between LSI 


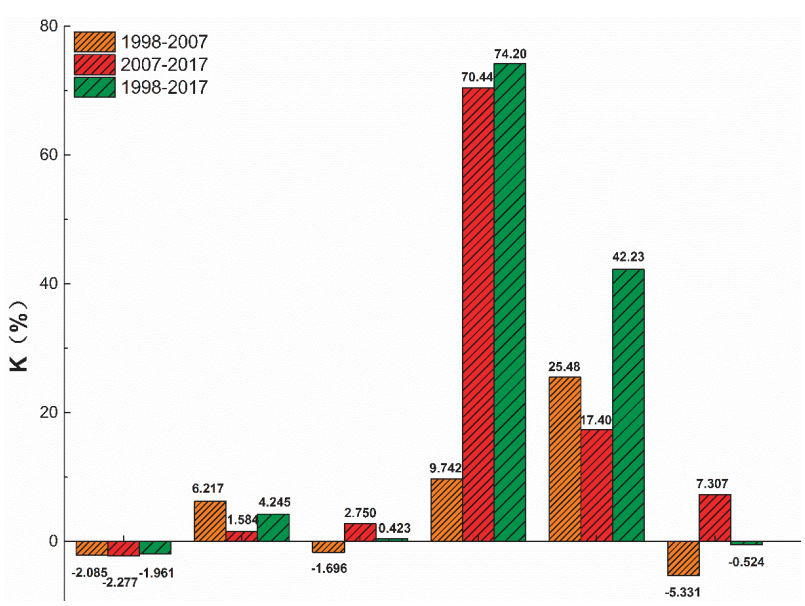

Fig. 6. The single land use dynamic degree of land use in Shanghai.

and PD. For AI and COHESION, between CA and LPI, and between LSI and PD. For AI and COHESION, they increased and then decreased for other land-use, increased for forestland, and changed little for cropland, water area and urban land. For CA and LPI, they
Table 6. The selection of an optimal grain size in this study.

\begin{tabular}{|c|c|c|}
\hline $\begin{array}{c}\text { Landscape } \\
\text { metrics }\end{array}$ & Method & $\begin{array}{c}\text { Appropriate grain } \\
\text { size (range) }\end{array}$ \\
\hline \multirow{2}{*}{ Class-level } & First scale domain & $60 \mathrm{~m}$ \\
\cline { 2 - 3 } & $\begin{array}{c}\text { Information loss } \\
\text { evaluation }\end{array}$ & $45-60 \mathrm{~m}$ \\
\hline Landscape-level & First scale domain & $>45 \mathrm{~m}$ \\
\hline Overall & & $60 \mathrm{~m}$ \\
\hline
\end{tabular}

decreased for cropland and increased for urban land, with little change observed for the other four land use types. For LSI and PD, they increased for cropland, forestland and grassland, and decreased and then increased for the other three land use types. DIVISION rose for cropland and declined for urban land but changed little for the other four land use types. In the case of ED, the value increased for cropland, urban land, and forestland but changed little for the other three land use types.

The four landscape-level metrics under the 60-m grain size computed in FRAGSTATS 4.2 were shown
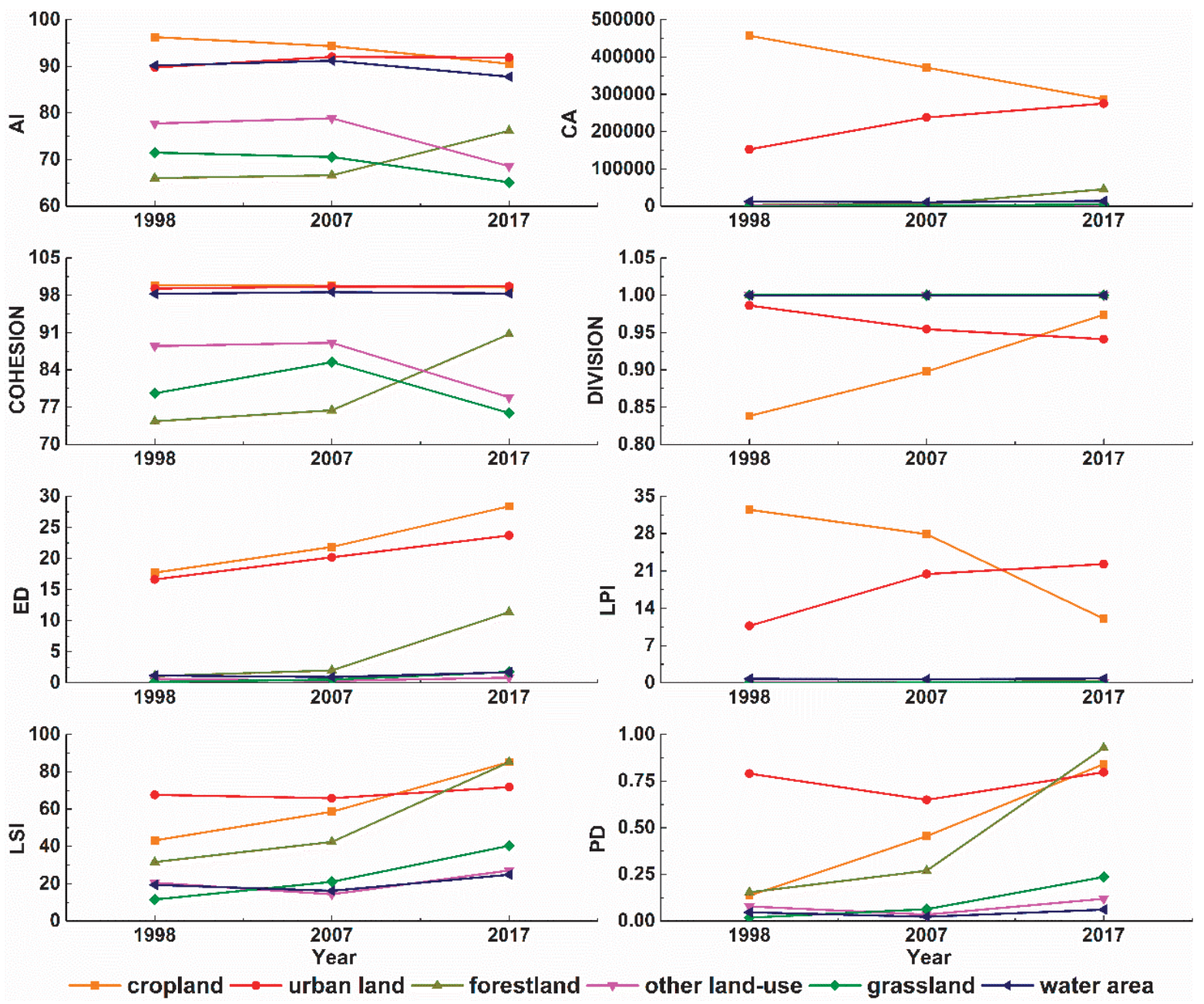

Fig. 7. The changes of land-use-specific class-level metrics over time under the optimal grain size (60 m). 


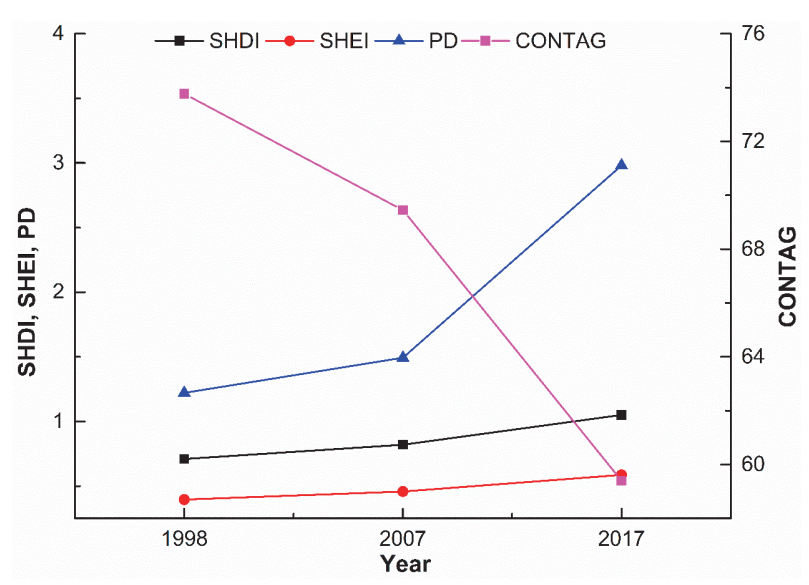

Fig. 8. The changes of landscape-level metrics over time under the optimal grain size $(60 \mathrm{~m})$.

Table 7. The overall land use dynamic degree of Shanghai.

\begin{tabular}{|c|c|c|c|}
\hline Year & $1998-2007$ & $2007-2017$ & $1998-2017$ \\
\hline$K S(\%)$ & 1.575 & 1.343 & 1.428 \\
\hline
\end{tabular}

in Fig. 8. SHDI, SHEI, and PD all increased over time though at various rates - the largest ascent was observed in PD during the 2007-2017 period. In contrast, CONTAG decreased over the two decades at a rising rate.

\section{Interpretation and Discussion}

\section{Responses of Landscape Metrics to Grain Size Change}

An improved understanding of the scale effect of landscape metrics is fundamental to reveal ecological processes and the impact of ecological environment change on rapidly urbanized areas $[65,66]$. Similar to the study of Teng et al. [8], our study shows that more than half of landscape metrics have high or moderate sensitivity to grain size change, except for the area (e.g. CA), separation (e.g. DIVISION), and landscape diversity (e.g. SHEI and SHDI) metrics. In another word, the response to grain size varies from metric to metric. While Buyantuyev and $\mathrm{Wu}$ [67] and Uuemaa et al. [23] claimed the trend of the responses of landscape metrics to grain size change could be increasing, decreasing or little change, Alhamad et al. [16] classified the responses into four types (i.e. predictable response, stair-like response, unstable response, and scale-based predictable response). In this study, there were three different response types, namely irregular trend (Type I), decreasing trend (Type II), and no clear change (Type III) (Fig. 3), which is partly consistent with previous studies [16, 23, 67]. The Type I response of class-level metrics corresponded with stair-like response reported by Alhamad et al. [16], whereas the Type II and Type III responses were also found by Uuemaa et al. [23]. Such variation in the categorization of the responses of landscape metrics to grain size change may be explained by the fact that these landscape metrics were computed for different landscape contexts [68]. Moreover, the responses and sensitivity of landscape metrics to increased grain size in different periods are basically the same [9].

Since human activity has a greater impact on cropland and settlements than natural landscape patches, the selection of landscape metrics and appropriate grain size should be carefully considered [5]. It is believed that under an optimal grain size, landscape pattern analysis can accurately reflect landscape characteristics, improve the efficiency of data processing, and reduce the loss of effective information [22]. Therefore, some studies have attempted to identify an optimal grain size for landscape pattern analysis. For example, Zhan et al. [9] found that turning points were important for determining optimal grain sizes from re-sampled data. Tian et al. [22] discovered that the information loss of landscape metrics was minimum at the $50 \mathrm{~m}$ grain size for a coastal wetland study, which could be used as the optimal grain size. On the one hand a finer grain size does not allow accurate modelling of landscape patterns [69] despite providing more details about landscape patterns, but on the other, coarse grain sizes could lead to incorrect results of landscape pattern analysis due to large information loss [9]. Considering the trade-off between an appropriate characterization of landscape patterns and the least information loss of data, an optimal grain size would be near the turning points with minor information loss. By combining the first scale domain and the information loss evaluation model, the optimal grain size was determined as $60 \mathrm{~m}$ for landscape pattern analysis in this study, which is similar to previous studies $[9,22,68]$.

\section{Analysis of Shanghai's Landscape Pattern}

Land use dynamic degree (LUDD) and landscape metrics would be useful tools for quantifying landscape patterns after determining the optimal grain size $(60 \mathrm{~m})$ $[63,67]$. Due to rapid urban expansion and economic development, Shanghai's landscape pattern changed drastically from 1998 to 2017 (Fig. 6 and Table 7). The area of cropland continued to decrease, whereas the area of urban land constantly increased despite a slowed growth rate (Fig. 6). Green spaces also grew, as indicated by the large and positive single land use dynamic degree of grassland and forestland (Fig. 6), mainly because of rising demand for a better quality of life [42] and the implementation of the $12^{\text {th }}$ Five-year Plan for Environmental Protection and Ecological Construction in Shanghai [70]. The overall land use dynamic degree decreased over time (Table 7), showing that the overall rate of land use change in Shanghai was slowing down from 1998 to 2017. 
With the highest urbanization rate in China [71], Shanghai witnessed accelerated transformation of landscape types and fragmentation of landscape patches due to intensified human activity and socio-economic development $[12,20]$. The class-level metrics of PD and LSI for all the land use types increased from 2007 to 2017 (Fig. 7), indicated that the complexity of landscape shapes gradually increased [10]. For the same land use type, landscape patterns also changed largely (Fig. 7). For example, the COHESION for grassland increased from 1998 to 2007 but decreased from 2007 to 2017 (Fig. 7), which is because of the change in driving forces that led to the evolution of landscape patterns [72]. Besides, Shanghai's landscape diversity increased (see SHDI and SHEI in Fig. 8), and the landscape aggregation showed a substantial decline (see CONTAG in Fig. 8). The continuous increase of the landscape-level metric PD (Fig. 8) reveals that landscape fragmentation showed a rising trend.

\section{Innovations and Limitations}

There is currently no universally recognized method for determining an optimal grain size for specific regions. As an optimal grain size is important for landscape pattern analysis, we here in this study used both the first scale domain method and the information loss evaluation model. Such approach allows for determining a more reliable optimal grain size, which guarantees the efficiency of landscape pattern analysis and retains the most information. Landscape pattern analysis based on such grain size is more effective in revealing the characteristics of landscaper pattern change.

However, the present study still needs to be improved. For instance, socio-economic data could be included to identify the driving factors accounting for Shanghai's landscape pattern change for an improved understanding of the urban landscape ecological process. Admittedly, remote sensing data were not the most recently acquired for this study. A direction for furthering the work is to establish a timeline for the evolution of urban landscape patterns by using more recent satellite imagery.

\section{Conclusions}

This study investigates the responses of landscape metrics to grain size change and analyses the change of landscape patterns based on an optimal grain size determined by an integrated use of the first scale domain method and the information loss evaluation model. The key findings and conclusions are as follows:

1. Shanghai's landscape pattern had an obvious grain effect, and the responses of landscape metrics to grain size change varied. The responses can be classified into three categories, namely irregular trend, decreasing trend, and no clear change.
2. The optimal grain size for landscape pattern analysis in the study area was $60 \mathrm{~m}$, which could better reveal landscape pattern features and help improve the efficiency of landscape pattern analysis while losing the least information.

3. From 1998 to 2017, Shanghai's landscape saw decreased aggregation and increased diversity and fragmentation. However, attributed to the implementation of environmental protection and ecological construction planning, urban green spaces had gradually increased in Shanghai.

This study showcases the selection of an optimal grain size for landscape pattern study and the characterization of urban landscape patterns based on such grain size. Moreover, findings from this study will be beneficial for decision-makers to formulate urban landscape protection strategies, thus improving the quality of urban ecological landscapes.

\section{Acknowledgements}

This research was funded by the National Natural Science Foundation of China (Grant No.: 42001212). Authors would like to thank the United States Geological Survey (USGS) for freely providing remote sensing image data and the editors and reviewers for their constructive comments.

\section{Conflict of Interest}

The authors declare no conflict of interest.

\section{References}

1. WU J., HOBBS R. Key issues and research priorities in landscape ecology: An idiosyncratic synthesis. Landscape Ecology, 17 (4), 355, 2002.

2. MAIROTA P., CAFARELLI B., LABADESSA R., LOVERGINE F., TARANTINO C., LUCAS R.M., NAGENDRA H., DIDHAM R.K. Very high resolution earth observation features for monitoring plant and animal community structure across multiple spatial scales in protected areas. International Journal of Applied Earth Observation and Geoinformation, 37, 100, 2015.

3. SCOWN M.W., THOMS M.C., DE JAGER N.R. Measuring floodplain spatial patterns using continuous surface metrics at multiple scales. Geomorphology, 245, 87, 2015.

4. SHI P., ZHANG Y., LI Z., LI P., XU G. Influence of land use and land cover patterns on seasonal water quality at multi-spatial scales. Catena, 151, 182, 2017.

5. FANG S., ZHAO Y., HAN L., MA C. Analysis of landscape patterns of arid valleys in China, based on grain size effect. Sustainability, 9 (12), 2263, 2017.

6. TURNER M.G., O'NEILL R.V., GARDNER R.H., MILNE B.T. Effects of changing spatial scale on the analysis of landscape pattern. Landscape Ecology, 3 (3-4), 153, 1989. 
7. TURNER M.G., DALE V.H., GARDNER R.H. Predicting across scales: Theory development and testing. Landscape Ecology, 3 (3-4), 245, 1989.

8. TENG M., ZENG L., ZHOU Z., WANG P., XIAO W., DIAN Y. Responses of landscape metrics to altering grain size in the Three Gorges Reservoir landscape in China. Environmental Earth Sciences, 75 (13), 1055, 2016.

9. ZHANG Q., CHEN C., WANG J., YANG D., ZHANG Y., WANG Z., GAO M. The spatial granularity effect, changing landscape patterns, and suitable landscape metrics in the Three Gorges Reservoir Area, 1995-2015. Ecological Indicators, 114, 106259, 2020.

10. ŠÍMOVÁ P., GDULOVÁ K. Landscape indices behavior: A review of scale effects. Applied Geography, 34, 385, 2012.

11. GRÊT-REGAMEY A., WEIBEL B., BAGSTAD K. J., FERRARI M., GENELETTI D., KLUG H., SCHIRPKE U., TAPPEINER U. On the effects of scale for ecosystem services mapping. PLoS ONE, 9 (12), e112601, 2014.

12. PLEXIDA S.G., SFOUGARIS A.I., ISPIKOUDIS I.P., PAPANASTASIS V.P. Selecting landscape metrics as indicators of spatial heterogeneity - A comparison among Greek landscapes. International Journal of Applied Earth Observation and Geoinformation, 26, 26, 2014.

13. ANDERSON C.D., EPPERSON B.K., FORTIN M.J., HOLDEREGGER R., JAMES P.M., ROSENBERG M.S., SCRIBNER K.T., SPEAR S. Considering spatial and temporal scale in landscape-genetic studies of gene flow. Molecular Ecology, 19 (17), 3565, 2010.

14. LUSTIG A., STOUFFER D.B., DOSCHER C., WORNER S.P. Landscape metrics as a framework to measure the effect of landscape structure on the spread of invasive insect species. Landscape Ecology, 32 (12), 2311, 2017.

15. SNYDER M.N., GOETZ S.J., WRIGHT R.K. Stream health rankings predicted by satellite derived land cover metrics. Journal of the American Water Resources Association, 41 (3), 659, 2005.

16. ALHAMAD M.N., ALRABABAH M.A., FEAGIN R.A., GHARAIBEH A. Mediterranean drylands: The effect of grain size and domain of scale on landscape metrics. Ecological Indicators, 11 (2), 611, 2011.

17. WHEATLEY M. Domains of scale in forest-landscape metrics: Implications for species-habitat modeling. Acta Oecologica, 36 (2), 259, 2010.

18. CASTILLA G., LARKIN K., LINKE J., HAY G.J. The impact of thematic resolution on the patch-mosaic model of natural landscapes. Landscape Ecology, 24 (1), 15, 2009.

19. BASTIN G.N., LUDWIG J.A., EAGER R.W., CHEWINGS V.H., LIEDLOFF A.C. Indicators of landscape function: comparing patchiness metrics using remotely-sensed data from rangelands. Ecological Indicators, 1 (4), 247, 2002.

20. INKOOM J.N., FRANK S., GREVE K., WALZ U., FÜRST C. Suitability of different landscape metrics for the assessments of patchy landscapes in West Africa. Ecological Indicators, 85, 117, 2018.

21. FENG Y., LIU Y. Fractal dimension as an indicator for quantifying the effects of changing spatial scales on landscape metrics. Ecological Indicators, 53, 18, 2015.

22. TIAN P., CAO L., LI J., PU R., SHI X., WANG L., LIU RUIQING, XU H.,TONG C., ZHOU Z., SHAO S. Landscape grain effect in Yancheng Coastal wetland and its response to landscape changes. International Journal of Environmental Research and Public Health, 16 (12), 2225, 2019.

23. UUEMAA E., ROOSAARE J., MANDER Ü. Scale dependence of landscape metrics and their indicatory value for nutrient and organic matter losses from catchments. Ecological Indicators, 5 (4), 350, 2005.

24. LECHNER A.M., LANGFORD W.T., BEKESSY S.A., JONES S.D. Are landscape ecologists addressing uncertainty in their remote sensing data? Landscape Ecology, 27 (9), 1249, 2012.

25. MCGARIGAL K., MARKS B.J. FRAGSTATS: spatial pattern analysis program for quantifying landscape structure. General Technical Report - US Department of Agriculture, Forest Service, 1995.

26. PARENT J.R., VOLIN J.C. Validating Landsat-based landscape metrics with fine-grained land cover data. Ecological Indicators, 60, 668, 2016.

27. OYANA T.J., JOHNSON S.J., WANG G. Landscape metrics and change analysis of a national wildlife refuge at different spatial resolutions. International Journal of Remote Sensing, 35 (9), 3109, 2014.

28. CONNOR T., HULL V., VIÑA A., SHORTRIDGE A., TANG Y., ZHANG J., WANG F., LIU J. Effects of grain size and niche breadth on species distribution modeling. Ecography, 41 (8), 1270, 2018.

29. LÜ Y., FENG X., CHEN L., FU B. Scaling effects of landscape metrics: a comparison of two methods. Physical Geography, 34 (1), 40, 2013.

30. BUYANTUYEV A., WU J., GRIES C. Multiscale analysis of the urbanization pattern of the Phoenix metropolitan landscape of USA: Time, space and thematic resolution. Landscape and Urban Planning, 94 (3-4), 206, 2010.

31. FROHN R., HAO Y. Landscape metric performance in analyzing two decades of deforestation in the Amazon Basin of Rondonia, Brazil. Remote Sensing of Environment, 100 (2), 237, 2006.

32. WU J., JELINSKI D.E., LUCK M., TUELLER P.T. Multiscale analysis of landscape heterogeneity: scale variance and pattern metrics. Geographic Information Sciences, 6, 6, 2000.

33. J.B. BALDWIN D., WEAVER K., SCHNEKENBURGER F., H. PERERA A. Sensitivity of landscape pattern indices to input data characteristics on real landscapes: implications for their use in natural disturbance emulation. Landscape Ecology, 19 (3), 255, 2004.

34. MILLINGTON A.C., VELEZ-LIENDO X.M., BRADLEY A.V. Scale dependence in multitemporal mapping of forest fragmentation in Bolivia: implications for explaining temporal trends in landscape ecology and applications to biodiversity conservation. ISPRS Journal of Photogrammetry and Remote Sensing, 57 (4), 289, 2003.

35. GARCÍA-FECED C., SAURA S., ELENA-ROSSELLÓ R. Assessing the effect of scale on the ability of landscape structure metrics to discriminate landscape types in Mediterranean forest districts. Forest Systems, 19 (2), 129, 2010.

36. YAMAKITA T., NAKAOKA M. Importance of considering grain and extent for the analysis on spatial dynamics: perspectives from comparison between theory and empirical example on seagrass bed dynamics in Tokyo Bay. Procedia - Social and Behavioral Sciences, 21, 177, 2011.

37. FAN Q., LIANG Z., LIANG L., DING S., ZHANG X. Landscape Pattern Analysis Based on Optimal Grain Size in the Core of the Zhengzhou and Kaifeng Integration Area. Polish Journal of Environmental Studies, 27 (3), 1229, 2018.

38. ZHAI J., HOU P., ZHAO Z., XIAO R., YAN C., NIE X. An analysis of landscape pattern spatial grain size effects 
in Qinghai Lake watershed. Remote Sensing for Land and Resources, 30 (3), 159, 2018 [In Chinese].

39. ZHANG R., PU L., ZHU M. Impacts of transportation arteries on land use patterns in urban-rural fringe: A comparative gradient analysis of Qixia District, Nanjing City, China. Chinese Geographical Science, 23 (3), 378, 2013.

40. YU L., ZHAO Y., ZHANG Y., LI M. Landscape pattern analysis of wetlands in the Daliaohe Watershed, based on optimal grain size. Acta Scientiae Circumstantiae, 31 (4), 873, 2011 [In Chinese].

41. Shanghai Municipal Statistics Bureau(SMSB). Available online: http://tjj.sh.gov.cn/tjgb/index.html (accessed on May 19, 2020).

42. WU Z., CHEN R., MEADOWS M.E., SENGUPTA D., XU D. Changing urban green spaces in Shanghai: trends, drivers and policy implications. Land Use Policy, 87, 104080, 2019.

43. Shanghai Master Plan 2017-2035. Available online: http:// www.shanghai.gov.cn/newshanghai/xxgkfj/2035004.pdf (accessed on May 19, 2020).

44. ROGAN J., CHEN D. Remote sensing technology for mapping and monitoring land-cover and land-use change. Progress in Planning, 61 (4), 301, 2004.

45. ROY D.P., WULDER M.A., LOVELAND T.R., WOODCOCK C.E., ALLEN R.G., ANDERSON M.C., HELDER D., IRONS J.R., JOHNSON D.M., KENNEDY R., SCAMBOS T.A., SCHAAF C.B., SCHOTT J.R., SHENG Y., VERMOTE E.F., BELWARD A.S., BINDSCHADLER R., COHEN W.B., GAO F., HIPPLE J.D., HOSTERT P., HUNTINGTON J., JUSTICE C.O., KILIC A., KOVALSKYY V., LEE Z.P., LYMBURNER L., MASEK J.G., MCCORKEL J., SHUAI Y.,TREZZA R.,VOGELMANN J., WYNNE R.H., ZHU Z. Landsat-8: Science and product vision for terrestrial global change research. Remote Sensing of Environment, 145, 154, 2014.

46. LALIBERTE A.S., RANGO A., HAVSTAD K.M., PARIS J.F., BECK R.F., MCNEELY R., GONZALEZ A.L. Object-oriented image analysis for mapping shrub encroachment from 1937 to 2003 in southern New Mexico. Remote Sensing of Environment, 93 (1-2), 198, 2004.

47. LI L., SOLANA C., CANTERS F., KERVYN M. Testing random forest classification for identifying lava flows and mapping age groups on a single Landsat 8 image. Journal of Volcanology and Geothermal Research, 345, 109, 2017.

48. CUI Y., LI L., CHEN L., ZHANG Y., CHENG L., ZHOU $\mathrm{X}$., YANG X. Land-use carbon emissions estimation for the Yangtze River Delta urban agglomeration using 19942016 Landsat image data. Remote Sensing, 10 (9), 1334, 2018.

49. ZHOU X., LI L., CHEN L., LIU Y., CUI Y., ZHANG Y., ZHANG T. Discriminating urban forest types from Sentinel-2A image data through linear spectral mixture analysis: A case study of Xuzhou, east China. Forests, $\mathbf{1 0}$ (6), 478, 2019.

50. LIU W., LI L., CHEN L., WEN M., WANG J., YUAN L., LIU Y.Q., LI H. Testing a comprehensive volcanic risk assessment of Tenerife by volcanic hazard simulations and social vulnerability analysis. ISPRS International Journal of Geo-Information, 9 (4), 273, 2020.

51. BREIMAN L. Random forests. In Intergovernmental Panel on Climate Change (Ed.), Climate Change 2013 The Physical Science Basis (Vol. 45, pp. 1-30). Cambridge: Cambridge University Press, 2001.
52. VAN DER LINDEN S., RABE A., HELD M., JAKIMOW B., LEITÃO P., OKUJENI A., SCHWIEDER M., SUESS S., HOSTERT P. The EnMAP-Box - A Toolbox and Application Programming Interface for EnMAP Data Processing. Remote Sensing, 7 (9), 11249, 2015.

53. LUCAS I.F.J., FRANS J.M., WEL V.D. Accuracy assessment of satellite derived land-cover data: A review. Photogrammetric Engineering and Remote Sensing, 60 (4), 410, 1994.

54. MCGARIGAL K. Landscape Pattern Metrics. In Encyclopedia of Environmetrics. Chichester, UK: John Wiley \& Sons, Ltd, 2006.

55. MCGARIGAL K., CUSHMAN S.A., NEEL M.C., ENE E. Spatial Pattern Analysis Program for Categorical and Continuous Maps. Available online: http://www.umass. edu/landeco/research/fragstats/fragstats.html (accessed on May 18, 2020).

56. UUEMAA E., ANTROP M., ROOSAARE J., MARJA R., MANDER Ü. Landscape metrics and indices: An overview of their use in landscape research. Living Reviews in Landscape Research, 3 (1), 2009.

57. KELLY M., TUXEN K. A., STRALBERG D. Mapping changes to vegetation pattern in a restoring wetland: Finding pattern metrics that are consistent across spatial scale and time. Ecological Indicators, 11 (2), 263, 2011.

58. CUSHMAN S.A., MCGARIGAL K., NEEL M.C. Parsimony in landscape metrics: Strength, universality, and consistency. Ecological Indicators, 8 (5), 691, 2008.

59. LI H., LI L., CHEN L., ZHOU X., CUI Y., LIU Y. Mapping and characterizing spatiotemporal dynamics of impervious surfaces using landsat images : A Case study of Xuzhou, east China from 1995 to 2018. Sustainability, 11, 1224, 2019.

60. YANG Q., LI J., GAN X., ZHANG J., YANG F., QIAN Y. Comparison of landscape patterns between metropolises and small-sized cities: A gradient analysis with changing grain size in Shanghai and Zhangjiagang, China. International Journal of Remote Sensing, 33 (5), 1446, 2012.

61. HAY G.J., MARCEAU D.J., DUBÉ P., BOUCHARD A. A multiscale framework for landscape analysis: Objectspecific analysis and upscaling. Landscape Ecology, 16 (6), 471, 2001.

62. YI H., ZHANG L., LUO W., WANG Y., YANG J., LI H., ZHOU T., FENG Z. Spatial grain size effect on land use pattern changes within the Yanghe watershed in 19902013.Chinese Agricultural Science Bulletin, 34 (19), 83, 2018 [In Chinese].

63. HUANG B., HUANG J., GILMORE PONTIUS R.,TU Z. Comparison of Intensity Analysis and the land use dynamic degrees to measure land changes outside versus inside the coastal zone of Longhai, China. Ecological Indicators, 89, 336, 2018.

64. ZHANG W., YAO L., LI H., SUN D., ZHOU L. Research on Land Use Change in Beijing Hanshiqiao Wetland Nature Reserve Using Remote Sensing and GIS. Procedia Environmental Sciences, 10, 583, 2011.

65. TURNE M. G. Landscape Ecology: The effect of pattern on process. Annual Review of Ecology and Systematics, 20, 171, 1989.

66. JOHNSON G.D., PATIL G.P. Quantitative multiresolution characterization of landscape Patterns for assessing the Status of ecosystem health in watershed management areas. Ecosystem Health, 4 (3), 177, 1998. 
67. BUYANTUYEV A., WU J. Effects of thematic resolution on landscape pattern analysis. Landscape Ecology, 22 (1), 7, 2007.

68. WU J., SHEN W., SUN W., TUELLER P.T. Empirical patterns of the effects of changing scale on landscape metrics. Landscape Ecology, 17, 761, 2002.

69. COSTANZA R., MAXWELL T. Resolution and predictability: An approach to the scaling problem. Landscape Ecology, 9 (1), 47, 1994.

70. The $12^{\text {th }}$ Five-year Plan for Environmental Protection and Ecological Construction in Shanghai. Available online: http://www.shanghai.gov.cn/shanghai/node2314/ node $25307 /$ node $25455 /$ node25459/u21ai602117.html (accessed on May 18, 2020).

71. China's urbanization rate ranked by provinces in 2019. Available online: https://s.askci.com/news/ hongguan/20200422/1346571159528.shtml (accessed on May 20, 2020).

72. POUDEVIGNE I., VAN ROOIJ S., MORIN P., ALARD D. Dynamics of rural landscapes and their main driving factors: A case study in the Seine Valley, Normandy, France. Landscape and Urban Planning, 38 (1-2), 93, 1997. 